(c) American Dairy Science Association, 2006.

\title{
Effects of Roughness and Compressibility of Flooring on Cow Locomotion
}

\author{
J. Rushen ${ }^{1}$ and A. M. de Passillé \\ Pacific Agri-Food Research Centre, Agriculture and Agri-Food Canada, Agassiz, British Columbia, Canada, V0M 1A0
}

\begin{abstract}
We examined the effects of roughness and degree of compressibility of flooring on the locomotion of dairy cows. We observed 16 cows walking down specially constructed walkways with materials that differed in surface roughness and degree of compressibility. Use of a commercially available soft rubber flooring material decreased slipping, number of strides, and time to traverse the corridor. These effects were most apparent at difficult sections of the corridor, such as at the start, at a right-angle turn, and across a gutter. Covering the walkway with a thin layer of slurry increased frequency of slipping, number of strides, and time taken to traverse the walkway. Effects of adding slurry were not overcome by increasing surface roughness or compressibility. Placing more compressible materials under a slip-resistant material reduced the time and number of steps needed to traverse the corridor but did not reduce slips, and the effects on cow locomotion varied nonlinearly with the degree of compressibility of the floor. Use of commercially available rubber floors improved cow locomotion compared with concrete floors. However, standard engineering measures of the floor properties may not predict effects of the floor on cow behavior well. Increasing compressibility of the flooring on which cows walk, independently of the roughness of the surface, can improve cow locomotion.

Key words: dairy cow, floor, locomotion, welfare
\end{abstract}

\section{INTRODUCTION}

Most research on cow comfort has focused on stall design, but for cows housed in free stalls, flooring surfaces outside the stall are of significant importance. Dairy cows in North America are increasingly housed on concrete floors (USDA, 2002). However, cattle choose to walk on floors that are soft (Gregory and Taylor, 2002) or that provide good traction (Phillips and Morris, 2001). The coefficient of friction of concrete floors is

Received October 11, 2005.

Accepted February 23, 2006

${ }^{1}$ Corresponding author: rushenj@agr.gc.ca often too low (Phillips and Morris, 2001; van der Tol et al., 2005; Telezhenko and Bergsten, 2005), especially when the floors are covered with slurry (Phillips and Morris, 2000). Adequate traction is especially important when the cow begins to walk, stops suddenly, or turns corners (van der Tol et al., 2005). In practice, the friction of floors usually is increased by grooving concrete floors, and increasing their surface roughness can improve some aspects of locomotion (Phillips and Morris, 2001). Hard flooring can considerably increase the pressure on the cow's hoof (Hinterhofer et al., 2005), however, and research shows that cows seem to avoid grooved, concrete floors (Stefanowska et al., 2002).

Furthermore, concrete floors have been associated with an increased incidence of lameness and hoof problems (Vokey et al., 2001; Somers et al., 2003; Cook et al., 2004). Poor flooring can impair locomotion (Jungbluth et al., 2003; van der Tol et al., 2005), increase the risk of injury (Weeks et al., 2002), and influence expression of estrus behavior (Lopez and Shipka, 2003).

Consequently, there is increased interest in alternative flooring materials for dairy barns, especially floors that have better friction and that are softer than concrete. More recently, a number of rubber-based materials, which also reduce the hardness of the floor, have increasingly been used and tested (Vokey et al., 2001; Fregonesi et al., 2004; Tucker et al., 2006). Although research has shown that cattle prefer softer floors when lying down (Manninen et al., 2002; Tucker et al., 2003), we know little about how the degree of compressibility of the flooring affects locomotion. Recent studies have shown that cows walk faster, walk with longer strides, and slip less often on softer rubber floors than on concrete floors (Jungbluth et al., 2003; Telezhenko and Bergsten, 2005), although the relative importance of surface roughness and degree of compressibility have not been explored. Our objective was to examine the advantages of alternative flooring and the effects of the slipperiness of the surface and the compressibility of flooring on the locomotion of dairy cows.

\section{MATERIALS AND METHODS}

\section{Animals and Housing}

We used 16 nonlactating Holstein dairy cows (parity between 2 and 6 , mean $\mathrm{BW}=650 \mathrm{~kg}$ ), housed in individ- 


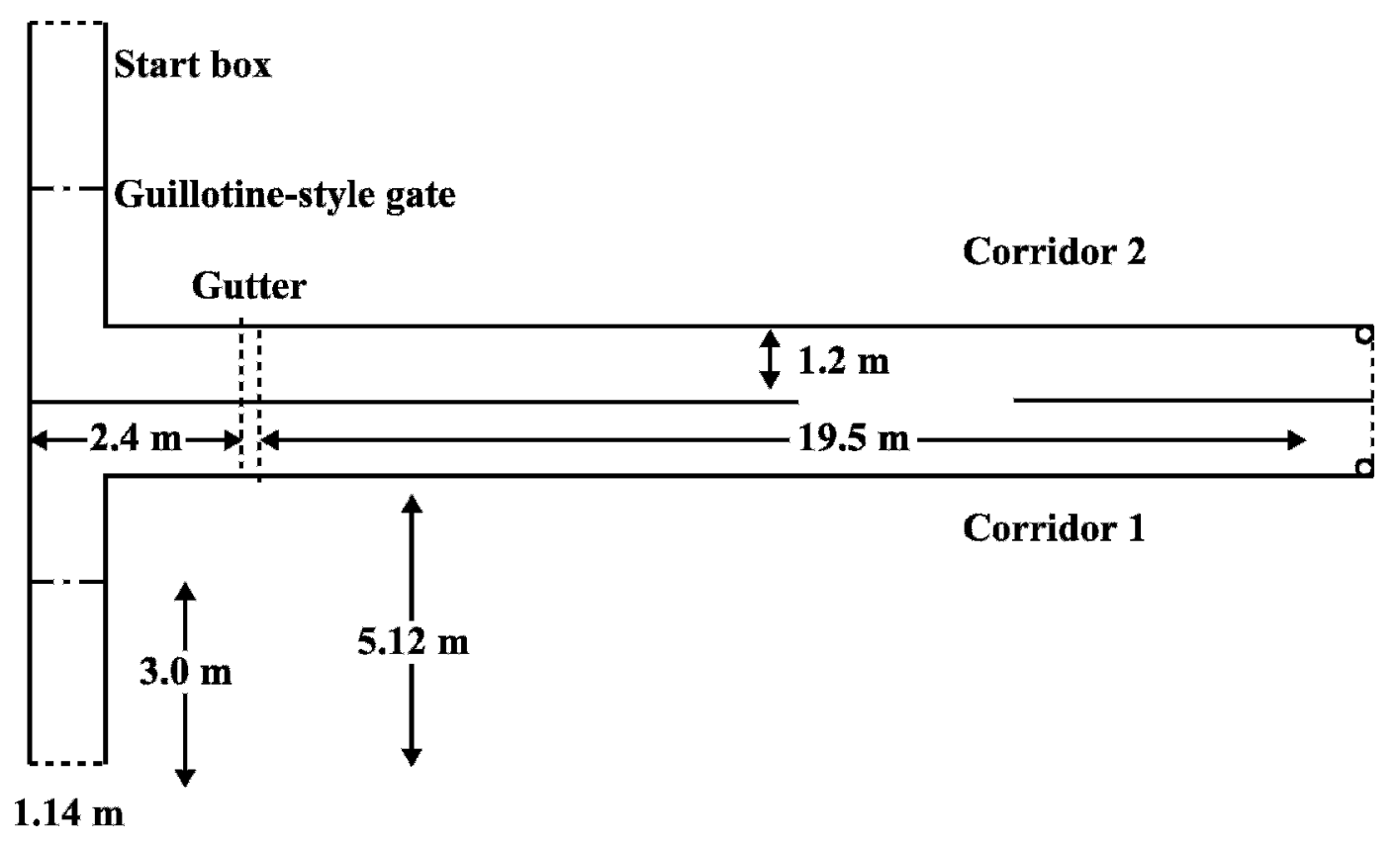

Figure 1. Plan showing the form and dimensions of the 2 walking corridors.

ual $1.4 \times 1.9-\mathrm{m}$ tie stalls, covered with PastureMat mattresses (Promat Inc., Seaforth, Ontario, Canada) with a small amount of sawdust bedding. Cows were fed a TMR and normally walked twice daily to the milking parlor. Most walking surfaces were covered with Animat (Animat Inc., Saint-Élie d'Orford, Quebec, Canada), although the cows regularly walked on concrete floors for short distances. The cows were not noticeably lame.

\section{General Procedures and Measures}

We examined the locomotion of cows while they were walking down specially constructed walkways with different flooring materials.

Walkways. We constructed 2 special L-shaped walkways that contained some of the challenges that cows face when walking (Figure 1). A small gutter, which the cows had to jump over, was placed after a rightangle turn in the corridor. The gutter was about $10 \mathrm{~cm}$ deep and was filled with straw. Walkways were in a separate room of the same barn in which cows were housed. Cows had not been in this room since they were calves. The start box had an Animat floor, a guillotinestyle gate that could be opened remotely, and open bars that allowed the cows to see the rest of the room. At the end of the passageway was a bucket that contained a small quantity of concentrate to provide a feeding reward for the cows when they reached the end of the passageway. Walls of the walkways, made of iron bars, were open and the walkways were separated by a wire fence that allowed the cow to see the rest of the room. The other flooring throughout the room was ungrooved concrete.

Cows were taken from their home stalls and moved in pairs to a waiting room, which was a room adjacent to the walkways. Cows were taken individually out of the waiting room and placed in the start box of the walkway. The cow remained in the start box for a few minutes, then the guillotine gate was opened. The cows were allowed to move down the walkway at their own speed while the handler followed the cow at a distance of 1 to $2 \mathrm{~m}$. If the cow stopped, the person waited for 2 $\mathrm{s}$. Then, if the cow had not recommenced walking, the handler moved toward the cow and gave her 2 light prods with a pencil. When the cow stopped at the gutter, the handler waited $7 \mathrm{~s}$ before encouraging the cow to move. Once the cow had arrived at the end of the passageway, she was allowed to eat the concentrate for 20 $\mathrm{s}$ before being returned to the start box. Any feces were removed from the passageway with a shovel. No other cows were in the room.

A total of 5 black-and-white video cameras were placed at various positions in the walkway, and all cameras fed into 2 multiplexers so that multiple cameras filming each position could be viewed simultaneously. Each passage was filmed concurrently by all cameras using a variable-speed video recorder. Videotapes were then viewed at 1/30th of normal speed ( $\sim 1$ frame/ $\mathrm{s}$ ), and when necessary, a frame-by-frame analysis was 
done to obtain precise measures of the time $( \pm 0.1 \mathrm{~s})$ the cow needed to traverse each section of the corridor and the number of steps taken. The same person watched all the videotapes of each cow.

The following measures were taken: 1) latency of leaving the start box, defined as the time when the guillotine door was fully elevated to the moment at which the last back leg crossed the exit line of the box; 2) time to traverse the initial corner, defined as when the last back leg first touched the floor at a point past the corner; 3) time taken to traverse the gutter, defined as the time for the last back leg to touch the floor after the gutter; 4) time to arrive at the end of the walkway, defined as when the cow stopped walking; 5) total time to traverse the walkway, based on the sum of the preceding events; and 6) the total number of steps taken by one defined foot of the cow, to estimate the average stride length.

In addition, we noted 1) each time the hooves slipped (where one or more feet were seen to slide visibly when they touched the floor); 2) each time the cow fell (when at least one knee or hock touched the floor; if a cow fell more than twice, she was removed from the study); and 3 ) each time the handler prodded the cow to encourage her to move forward.

\section{Specific Experimental Procedures}

Experiment 1. The aim of this experiment was to compare the effects of a concrete floor and a more compressible commercially available rubber floor, both when dry and when covered with slurry.

The 16 cows were allotted randomly to 2 groups. During 28 initial habituation trials (14 on each walkway), cows were moved down both walkways with the normal, worn concrete floor according to the procedure described previously. One-half the cows in each group first walked on walkway 1 , and the other half first walked on walkway 2 . Following this test, the walkways were alternated from one passage to the next.

We then compared 2 types of flooring materials: normal concrete flooring and Animats (Animat Inc.), which are composed of a soft revulcanized rubber $(19 \mathrm{~mm}$ thick) with small burls to improve friction. Interlocking Animats covered the entire floor of one passageway. The coefficient of friction and degree of compressibility of the Animats and concrete (Table 1) were tested when dry by the Centre de Recherche Industrielle du Québec (Ste-Foy, Quebec, Canada) using standard engineering techniques (CRIQ, 2005).

For cows in group 1, the Animats were placed in corridor 1, whereas for those in group 2, the Animats were placed in corridor 2 . We completed trials for group 1 before beginning the trials for group 2 . Each day, each
Table 1. Static and dynamic coefficients of friction (COF) and degree of compressibility of the various flooring materials ${ }^{1}$

\begin{tabular}{|c|c|c|c|c|c|}
\hline \multirow{2}{*}{$\begin{array}{l}\text { Type } \\
\text { of material }\end{array}$} & \multicolumn{2}{|c|}{$\mathrm{COF}^{2}$} & \multicolumn{3}{|c|}{$\begin{array}{c}\text { Compressibility }{ }^{3} \\
\mathrm{~N} / \mathrm{cm}^{2}\end{array}$} \\
\hline & Static & Dynamic & 34.3 & 68.6 & 137.2 \\
\hline Concrete & 0.36 & 0.28 & $1.0^{4}$ & 1.4 & 2.0 \\
\hline Animat $^{5}$ & 0.61 & 0.47 & 3.2 & 4.3 & 6.7 \\
\hline Nonslip material & 0.70 & 0.47 & 4.1 & 5.2 & 6.4 \\
\hline
\end{tabular}

${ }^{1}$ Based on data from the Centre de Recherche Industrielle du Québec (CRIQ, 2005).

${ }^{2}$ Coefficients of friction measured according to standard ASTM D 1894 using maple as a reference material and a $1-\mathrm{kg}$ vertical load. Static friction refers to the minimum force needed to move a stationary object, whereas dynamic friction refers to the minimum force needed to maintain movement of a moving object. In this case, a velocity of $2.5 \mathrm{~mm} / \mathrm{s}$ was used in the measurement of dynamic friction.

${ }^{3}$ Compressibility measured according to standard ASTM D 575. A sample of each surface material was placed on a flat surface and pressures of $34.3,68.6$, and $137.2 \mathrm{~N} / \mathrm{cm}^{2}$ were applied to a circular 12.7-cm-diameter object placed on the surface of each material. Extent of penetration of the object into the surface material was then measured using an Instron tensile tester, model 55R4206 (Instron, Norwood, MA). All measures were made in triplicate.

${ }^{4}$ Values set as a proportion of the value for concrete at $34.3 \mathrm{~N} / \mathrm{cm}^{2}$.

${ }^{5}$ Animat Inc., Saint-Élie d'Orford, Quebec, Canada.

cow was walked twice on each material for a total of 3 d (6 passages per material). During the experiments, we alternated the walkways from one trial to the next.

We also compared the effects of dry floors and floors covered with slurry. For the latter, we covered both corridors with 1 to $5 \mathrm{~mm}$ of a mixture of cow feces and urine. Half of the cows walked first on dry Animat floors and on dry concrete floors, and then on both floors when covered with slurry. The other half of the cows first walked on the floors when covered with slurry, and then on dry floors. Each cow walked a total of 6 passages in each of the 4 treatments.

Experiment 2. The previous experiment compared Animats and concrete flooring, which differed both in the degree of compressibility and in the degree of friction. In this experiment, we used a second material, which had frictional and hardness characteristics similar to the Animat at low pressures but which was thinner $(64 \mathrm{~mm})$ and therefore less compressible at high pressures (Table 1). We used a high-friction slip-resistant material used principally on conveyor belts (\#125 2 ply; Cobelt Canada Inc., St. Bruno, Quebec, Canada).

We used the same 16 cows and the same experimental design as in Experiment 1. Each cow walked 6 times on each surface both when dry and when covered with 1 to $5 \mathrm{~mm}$ of a mixture of cow feces and urine. Each cow walked 4 passages per day (2 on concrete and 2 on the high-friction flooring), with the flooring either dry or covered with slurry on alternate days, for a total of 6 passages in each of the 4 treatments. 
Experiment 3. The degree of friction provided by a soft floor depends on the roughness of the surface material, but also on the extent to which the hooves penetrate the flooring material. In this experiment, we attempted to examine the effect of the degree of compressibility independent of the degree of floor roughness.

We used the same 16 cows and the same experimental design as before, except that the walking surfaces were always dry. On the top of both walkways, we used the same high-friction slip-resistant material as used in Experiment 2. In one walkway, we placed the material directly on the concrete, whereas on the other walkway, we placed the same slip-resistant material on 1 of 3 different materials that was more compressible than concrete to differing degrees. The other materials were: Animat, felt (1.5-m thick polypropylene-polyester mix), and PastureMat (7-cm thick geotextile-covered recycled rubber mattresses; Promat Inc., Seaforth, Ontario, Canada). The relative degrees of compressibility at $137.2 \mathrm{~N} / \mathrm{cm}^{2}$ of the 3 materials covered with nonslip material were as follows: concrete, 1; Animat, 2.05; felt, 5.23; and PastureMat, 10.11 (CRIQ, 2005). Each of the alternative materials was compared with concrete in 3 consecutive experiments. In each experiment, each cow walked 2 passages per day (one on concrete and one on the alternative material) for a total of 6 passages on each of the 3 materials.

\section{Statistical Analyses}

Because of a positive skew in the distribution of many of the results, the data were ranked before analysis. Preliminary tests showed that square root and log transformations achieved the same pattern of significance. The mixed models procedure of SAS (SAS Institute, 1999) was used to test the effects of treatments with cow as a random factor, treatments (type of flooring material, presence or absence of slurry) as main factors, passage as a repeated measure, and interactions between the type of floor and the presence or absence of slurry (Experiments 1 and 2). The incidence of slips and interventions by the handlers were highly variable between cows and were too infrequent to analyze as above. Consequently, Wilcoxon signed-rank tests were used to test differences between flooring types and between wet and dry conditions in the number of slips and interventions summed over all trials, and $\chi^{2}$ or Fisher exact tests (when expected frequencies were small) were used to examine the number of cows that slipped.

\section{RESULTS}

\section{Experiment 1}

For the passages on different flooring types, flooring type and dryness of the floor had significant effects on several variables, but no interaction was detected between these 2 factors for any of the measured variables (Table 2). The total passage time was smaller on Animats than on concrete: The cows took less time to start, turn the corner, and cross the gutter (Table 2). Cows also took fewer steps and slipped less often on the Animat flooring than on concrete (Table 2).

Effects of adding slurry were almost opposite those of using Animats (Table 2). When the floor was dry, the total passage time was shorter because the cows took less time to start, turn the corner, and cross the final section (Table 2). No differences were detected in the time taken to cross the gutter. Cows took fewer steps and slipped less often on dry floors (Table 2).

There was no evidence of any interaction between the type of floor and the presence of slurry. For example, the effects of the presence of slurry on the total time to complete the passage were similar for both concrete flooring (dry mean $=24.2 \mathrm{~s}$ vs. slurry mean $=25.9 \mathrm{~s}$; $\mathrm{SE}=0.8$ ) and Animat flooring (dry mean $=22.4 \mathrm{~s}$ vs. slurry mean $=24.1 \mathrm{~s} ; \mathrm{SE}=0.8$ ).

\section{Experiment 2}

One cow fell twice on the wet floor and was removed from the experiment. The effects of floor type were less evident than in Experiment 1 (Table 3). There was a trend $(P=0.10)$ for the total passage time to be shorter with the slip-resistant material, mainly because the cows took less time to cross the gutter and traverse the final section. Cows took fewer steps, but no differences in the incidence of slipping were detected (Table 3 ).

More cows slipped when the floor was covered in slurry ( 7 vs. 2 ; Fisher exact test, $P=0.04$ ) compared with dry flooring, but, in contrast to Experiment 1, few significant effects of the presence of slurry were detected for other aspects of cow locomotion. Frequency of encouragement by the handler was greater on the dry floor (Table 3).

No significant interactions were detected between floor type and floor dryness on any measure. For example, effects of the presence of slurry on the total time to complete the passage were similar for both concrete flooring $($ dry mean $=26.3 \mathrm{~s}$ vs. slurry mean $=26.7 \mathrm{~s}$; $\mathrm{SE}=0.8$ ) and flooring covered with the nonslip material $($ dry mean $=25.2 \mathrm{~s}$ vs. slurry mean $=24.8 \mathrm{~s} ; \mathrm{SE}=1.3)$. We detected a trend $(P=0.07)$ for the curve time to be reduced less by slurry on the nonslip material than on concrete (concrete: dry mean $=2.9 \mathrm{~s}$ vs. slurry mean $=$ 
Table 2. Mean values ( \pm SE) for times taken to traverse the walkway or each section of the walkway, number of steps taken, proportion of cows that slipped, and frequency of intervention by the handler for 16 cows walking on concrete, Animats, ${ }^{1}$ dry floors, or floors covered with slurry

\begin{tabular}{|c|c|c|c|c|c|c|c|}
\hline \multirow[b]{2}{*}{ Variable } & \multicolumn{2}{|c|}{ Floor type } & \multirow[b]{2}{*}{$P$} & \multicolumn{2}{|c|}{ Condition } & \multirow[b]{2}{*}{$P$} & \multirow{2}{*}{$\begin{array}{l}\text { Floor } \times \\
\text { condition } P\end{array}$} \\
\hline & Concrete & Animat & & Slurry & Dry & & \\
\hline Total time, $\mathrm{s}$ & $25.0 \pm 0.7$ & $23.2 \pm 0.7$ & $<0.001$ & $25.0 \pm 0.7$ & $23.3 \pm 0.7$ & 0.003 & $>0.10$ \\
\hline Start latency, s & $3.0 \pm 0.2$ & $2.4 \pm 0.2$ & $<0.001$ & $2.9 \pm 0.2$ & $2.5 \pm 0.2$ & 0.008 & $>0.10$ \\
\hline Curve time, $\mathrm{s}$ & $3.1 \pm 0.1$ & $2.4 \pm 0.1$ & $<0.001$ & $2.7 \pm 0.1$ & $2.8 \pm 0.1$ & $>0.10$ & $>0.10$ \\
\hline Gutter time, $\mathrm{s}$ & $5.0 \pm 0.2$ & $4.7 \pm 0.2$ & 0.02 & $4.9 \pm 0.2$ & $4.7 \pm 0.2$ & 0.09 & $>0.10$ \\
\hline End time, $\mathrm{s}$ & $14.0 \pm 0.5$ & $13.7 \pm 0.5$ & $>0.10$ & $14.5 \pm 0.5$ & $13.2 \pm 0.5$ & $<0.001$ & $>0.10$ \\
\hline Steps, no. & $34.3 \pm 0.3$ & $33.0 \pm 0.3$ & $<0.001$ & $34.2 \pm 0.3$ & $33.1 \pm 0.3$ & 0.001 & $>0.10$ \\
\hline Slips, no. & $1.8 \pm 0.5$ & $0.5 \pm 0.4$ & 0.04 & $1.8 \pm 0.5$ & $0.5 \pm 0.2$ & 0.009 & $>0.10$ \\
\hline Interventions, no. & $3.7 \pm 0.6$ & $3.1 \pm 1.0$ & $>0.10$ & $3.9 \pm 0.9$ & $2.9 \pm 0.7$ & 0.06 & $>0.10$ \\
\hline
\end{tabular}

${ }^{1}$ Animat Inc., Saint-Élie d’Orford, Quebec, Canada.

$3.2 \mathrm{~s}$; nonslip material: dry mean $=3.2 \mathrm{~s}$ vs. slurry mean $=2.7 \mathrm{~s} ; \mathrm{SE}=0.3$ ).

\section{Experiment 3}

Effects of the 3 types of softer flooring are shown in Table 4. There were no effects of the softer flooring on the incidence of slipping or on the need for handlers to encourage the cows to walk. Significant effects were found mainly with PastureMats. With PastureMats, the cows took fewer steps to traverse the walkway and the time taken to traverse the walkway was shorter (Table 4). There was a similar trend $(P=0.09)$ for time to traverse the corridor with Animats, and the cows took less time to turn the corner (Table 4). When felt was used, however, few significant effects were found, and the time to turn the corner was longer (Table 4).

\section{DISCUSSION}

Our results clearly showed advantages for cow locomotion of a commercially available soft rubber mat compared with ungrooved concrete. Cows slipped less often, took less time, and took fewer strides to traverse the runway on the Animats. These results imply that mean walking speed and stride length were increased, supporting previous research on rubber mats (Jungbluth et al., 2003; Telezhenko and Bergsten, 2005). Reductions in walking speed and stride length on slippery floors are likely to be adaptive mechanisms made by cows to reduce the chances of slipping and falling (Gronqvist et al., 2001). The coefficient of friction for our concrete surface was similar to that reported previously by Phillips and Morris (2001). The coefficient of friction for Animat flooring was considerably greater and came closer to the minimum values required for unhindered locomotion by cows (van der Tol et al., 2005). However, the engineering tests used probably underestimated the coefficient of friction for the softer Animat because the degree the hoof penetrates the softer material was not taken into account.

Although we did not measure walking speed directly, on the final straight part of the walkway, we estimated these speeds to have been between 1.4 and $1.5 \mathrm{~m} / \mathrm{s}(\sim 5$ $\mathrm{km} / \mathrm{h}$ ), slightly faster than the speed reported by others (Phillips and Morris, 2000, 2001; Telezhenko and Bergsten, 2005).

We used walking corridors that included some of the challenges faced by cows when walking. van der Tol et al. (2005) found that required coefficients of friction

Table 3. Mean values ( \pm SE) for times taken to traverse the walkway or each section of the walkway, number of steps taken, proportion of cows that slipped, and frequency of intervention by the handler for 15 cows walking on concrete, concrete covered with nonslip material, dry floors, or floors covered with slurry

\begin{tabular}{|c|c|c|c|c|c|c|c|}
\hline \multirow[b]{2}{*}{ Variable } & \multicolumn{2}{|c|}{ Floor type } & \multirow[b]{2}{*}{$P$} & \multicolumn{2}{|c|}{ Condition } & \multirow[b]{2}{*}{$P$} & \multirow{2}{*}{$\begin{array}{l}\text { Floor } \times \\
\text { condition } P\end{array}$} \\
\hline & Concrete & Nonslip & & Slurry & Dry & & \\
\hline Total time, $\mathrm{s}$ & $26.5 \pm 1.2$ & $25.0 \pm 1.2$ & 0.10 & $25.7 \pm 1.2$ & $25.8 \pm 1.2$ & $>0.10$ & $>0.10$ \\
\hline Start latency, s & $3.1 \pm 0.2$ & $3.4 \pm 0.2$ & $>0.10$ & $3.3 \pm 0.2$ & $3.2 \pm 0.2$ & $>0.10$ & 0.07 \\
\hline Curve time, $\mathrm{s}$ & $3.0 \pm 0.2$ & $2.9 \pm 0.2$ & $>0.10$ & $2.9 \pm 0.2$ & $3.0 \pm 0.2$ & $>0.10$ & $>0.10$ \\
\hline Gutter time, $\mathrm{s}$ & $5.0 \pm 0.3$ & $4.4 \pm 0.3$ & 0.01 & $4.7 \pm 0.3$ & $4.7 \pm 0.3$ & $>0.10$ & $>0.10$ \\
\hline End time, $\mathrm{s}$ & $15.3 \pm 0.7$ & $14.3 \pm 0.7$ & 0.02 & $14.8 \pm 0.7$ & $14.8 \pm 0.7$ & $>0.10$ & $>0.10$ \\
\hline Steps, no. & $34.7 \pm 0.2$ & $33.5 \pm 0.2$ & 0.01 & $34.2 \pm 0.2$ & $34.0 \pm 0.2$ & $>0.10$ & $>0.10$ \\
\hline Slips, no. & $2.1 \pm 0.6$ & $1.1 \pm 0.4$ & $>0.10$ & $3.0 \pm 0.7$ & $0.3 \pm 0.2$ & 0.003 & $>0.10$ \\
\hline Interventions, no. & $3.3 \pm 1.0$ & $4.7 \pm 1.4$ & $>0.10$ & $2.9 \pm 0.8$ & $5.0 \pm 1.5$ & 0.06 & $>0.10$ \\
\hline
\end{tabular}


Table 4. Mean values $( \pm$ SE) for times taken to traverse the walkway or each section of the walkway, number of steps taken, proportion of cows that slipped, and frequency of intervention by the handler for 16 cows walking on nonslip material ${ }^{1}$ placed either on concrete or on one of 3 more compressible materials

\begin{tabular}{|c|c|c|c|c|c|c|c|c|c|}
\hline Variable & \multicolumn{2}{|c|}{ Floor type } & $P$ & \multicolumn{2}{|c|}{ Floor type } & $P$ & \multicolumn{2}{|c|}{ Floor type } & $P$ \\
\hline Total time, s & $23.8 \pm 1.3$ & $21.0 \pm 1.3$ & 0.09 & $24.6 \pm 2.4$ & $25.7 \pm 2.4$ & $>0.10$ & $25.4 \pm 1.4$ & $22.6 \pm 1.4$ & 0.02 \\
\hline Curve time, $\mathrm{s}$ & $2.6 \pm 0.2$ & $2.3 \pm 0.2$ & 0.04 & $3.1 \pm 0.4$ & $4.0 \pm 0.4$ & 0.03 & $3.8 \pm 0.4$ & $2.7 \pm 0.4$ & 0.01 \\
\hline Gutter time, $\mathrm{s}$ & $4.2 \pm 0.3$ & $4.2 \pm 0.3$ & $>0.10$ & $4.5 \pm 0.5$ & $4.4 \pm 0.5$ & $>0.10$ & $4.7 \pm 0.4$ & $4.4 \pm 0.4$ & $>0.10$ \\
\hline End time, s & $13.1 \pm 0.6$ & $12.2 \pm 0.6$ & $>0.10$ & $14.5 \pm 1.4$ & $13.9 \pm 1.4$ & $>0.10$ & $14.2 \pm 0.9$ & $12.8 \pm 0.9$ & $>0.10$ \\
\hline Steps, no. & $32.8 \pm 0.6$ & $31.5 \pm 0.6$ & $>0.10$ & $32.5 \pm 0.9$ & $32.4 \pm 0.9$ & $>0.10$ & $32.6 \pm 0.5$ & $31.2 \pm 0.5$ & 0.004 \\
\hline
\end{tabular}

${ }^{1}$ All flooring was covered with the same nonslip material.

${ }^{2}$ Animat Inc., Saint-Élie d'Orford, Quebec, Canada.

${ }^{3}$ Promat Inc., Seaforth, Ontario, Canada.

were particularly large when cows were starting to walk compared with straight walking. For example, rightangle turns are a common source of injury in cattle (Weeks et al., 2002). The advantages of Animats were most apparent in the more challenging areas of the corridor, where traction was most needed (van der Tol et al., 2005). These included time to begin moving, time to leave the start box, time needed to turn the corner, and time needed to cross the gutter. Admittedly, the small times needed to complete these sections were close to the limits of accuracy of our timing $( \pm 0.1 \mathrm{~s})$. These differences between the materials were less apparent on the final, straight section of the corridor, in which traction may have been less important.

In Experiment 2, we used another slip-resistant flooring material that had a coefficient of friction and compressibility similar to the Animat flooring. Although the direction of the effects was similar in the 2 experiments, their magnitude was much lower with the second material. The use of slip-resistant material increased stride length, but effects on overall time to complete the passage failed to reach statistical significance. However, there was a reduction in the time needed to cross the gutter and to traverse the final, straight section. Although the slip-resistant material was more compressible than Animat flooring at pressures similar to those exerted when cows stand (maximum $75 \mathrm{~N} / \mathrm{cm}^{2}$; van der Tol et al., 2002), the material was thinner and became less compressible at greater pressures (Table 1). When cows walk, they can generate considerable vertical force on the floor (van der Tol et al., 2005), and a thinner nonslip flooring may not have been able to absorb these greater forces and pressures. Alternatively, the likelihood that the cows' hooves could have penetrated the thicker Animats more than the thinner material may have increased the contact surface between the hoof and the floor, as has been reported for horses (Hood et al., 2001). This greater penetration may have improved overall traction.

The coefficient of friction of a surface is often a good predictor of the degree of slipperiness of the floor (Chang et al., 2001), but our results showed that use of such standardized engineering measures alone had only limited ability to predict the effects of the flooring material on cow locomotion (Phillips and Morris, 2000; Gronqvist et al., 2001; Telezhenko and Bergsten, 2005). The actual degree of traction and compressibility will vary with the type of flooring material used, the speed of movement, and the actual surface area in contact with the floor, which are very hard to simulate (Gronqvist et al., 2001). Table 1 likely underestimates the coefficient of friction for cows' walking because the extent that the hoof can penetrate the softer material was not accounted for. Direct observations of behavior and of the actual force exerted by cows when walking (van der Tol et al., 2005) are therefore necessary to assess the adequacy of a flooring material in dairy barns. As our results show, use of slow-motion video can detect quite small changes in walking speed.

In both experiments, covering the walking surface with a thin layer of slurry greatly increased the incidence of slipping by the cows. In Experiment 1, the slurry had many effects on other aspects of locomotion opposite those of the Animats. Time and number of strides to cross the runway increased, confirming the findings of Phillips and Morris (2000). For reasons we do not understand, the effects of slurry on walking time and number of strides were not apparent during the second experiment. Perhaps differences existed in the depth and consistency of the slurry, which have been shown to moderate the effects on locomotion (Phillips and Morris, 2000). Interestingly, the effect of slurry was equally apparent on ungrooved concrete and on the Animat and the nonslip materials, although a nonsig- 
nificant trend occurring in Experiment 2 showed that the time to turn the corner was less affected by slurry on the nonslip material than on concrete. This general lack of interaction between the flooring material and the effects of slurry indicated that the improved dynamic friction of these other surfaces was insufficient to overcome the loss of friction because of the slurry. This shows the importance of keeping walking areas as clean and dry as possible to ensure good locomotion rather than relying on nonslip flooring. In addition, hooves absorb water quickly and consequently become soft (Borderas et al., 2004).

Animat flooring is more compressible and has greater surface friction than concrete. Previously, Phillips and Morris (2001) showed that increasing the surface friction without increasing the softness of the floor did not increase walking speed, although gait was altered. This indicates that the extra compressibility of Animat contributes to greater walking speed. In Experiment 3, we examined the effects of the degree of compressibility of the floors independent of the degree of roughness of the surface. We kept surface roughness constant by using the same thin, high-friction surface. We altered the degree of compressibility by maintaining the same surface material but placing this over underlays of different degrees of softness. However, we did not find a direct relationship between aspects of locomotion and degree of compressibility.

Positive effects on locomotion were most obvious when the most highly compressible material, PastureMat, was placed under the high-friction material. This reduced the time and number of strides required to traverse the runway. An increase in speed was most apparent when cows were turning the corner, although there was no change in the frequency of slipping. With Animats, the least compressible of the 3 , the effects on overall walking speed failed to reach significance, although the time needed to turn the corner was reduced. Although the PastureMats were much more compressible than the Animats, the magnitude of difference in their effects on locomotion was small (especially when comparing the results of Experiments 1 and 3). These small differences indicated that the degree of compressibility provided by Animats may be sufficient and there is little advantage in making walking surfaces much softer. Placing felt under the high-friction material, which resulted in a degree of compressibility between that of PastureMats and that of Animats, had no effect on overall walking speed, and in fact tended to increase the time cows needed to start walking and turn the corner. We cannot explain this finding, but it reinforces the point that standardized engineering measures of the physical properties of flooring may not predict the effects on the behavior of cows.

\section{CONCLUSIONS}

Use of rubber floors that provide more friction and more compressibility than concrete can increase the speed of cow locomotion and reduce chances of slipping. Both increased surface roughness and increased compressibility seem to contribute to this effect, although floors that are too soft may not provide secure footing. Engineering measures may have only limited usefulness in predicting effects of walking surfaces on locomotion. Direct observations of behavior are needed to assess the acceptability of flooring. Floors covered with slurry increase the risk of slips, and this may not be reduced by the use of nonslip flooring. Increasing the traction of floors by using softer rubber flooring may have advantages for the welfare and efficiency of moving cattle.

\section{ACKNOWLEDGMENTS}

This research was supported by a grant from the Dairy Farmers of Canada and Matching Investment Initiative funds from Agriculture and Agri-Food Canada. We thank Dan Weary and Peter Phillips for useful discussions, and Marjolaine St-Louis, Isabelle Blanchet, Wendy King, Evelyne Lepron, Marie Lavoie, and the staff of the Lennoxville dairy barn for their help. We also thank Michel Comeau of CRIQ for providing us with data on the physical properties of the materials.

\section{REFERENCES}

Borderas, T. F., B. Pawluczuk, A. M. de Passillé, and J. Rushen. 2004. Claw hardness of dairy cows: Relationship to water content and claw lesions. J. Dairy Sci. 87:2085-2093.

Chang, W. R., I. J. Kim, D. P. Manning, and Y. Bunterngchit. 2001. The role of surface roughness in the measurement of slipperiness. Ergonomics 44:1200-1216.

Cook, N. B., K. V. Nordlund, and G. R. Oetzel. 2004. Environmental influences on claw horn lesions associated with laminitis and subacute ruminal acidosis in dairy cows. J. Dairy Sci. 87(E. Suppl.):E36-E46.

CRIQ. 2005. Caractérisation de Matériaux de Surface pour Bovines laitiers. Rapport technique, Dossier CRIQ 640-PE33790. Centre de Recherche Industrielle du Québec, Ste-Foy, Quebec.

Fregonesi, J. A., C. B. Tucker, D. M. Weary, F. C. Flower, and T. Vittie. 2004. Effect of rubber flooring in front of the feed bunk on the time budgets of dairy cattle. J. Dairy Sci. 87:1203-1207.

Gregory, N. G., and O. D. Taylor. 2002. Dairy cow preference for a soft track surface. N. Z. Vet. J. 50:83.

Gronqvist, R., W. R. Chang, T. K. Courtney, T. B. Leamon, M. S. Redfern, and L. Strandberg. 2001. Measurement of slipperiness: Fundamental concepts and definitions. Ergonomics 44:11021117.

Hinterhofer, C., J. C. Ferguson, V. Apprich, H. Haider, and C. Stanek. 2005. A finite element model of the bovine claw under static load for evaluation of different flooring conditions. N. Z. Vet. J. 53:165-170.

Hood, D. M., D. Taylor, and I. P. Wagner. 2001. Effects of ground surface deformability, trimming, and shoeing on quasistatic hoof loading patterns of horses. Am. J. Vet. Res. 62:895-900. 
Jungbluth, T., B. Benz, and H. Wandel. 2003. Soft walking areas in loose housing systems for dairy cows. Pages 171-177 in Proc. 5th. Int. Dairy Housing Conf. ASAE, Fort Worth, TX.

Lopez, H., and M. P. Shipka. 2003. Association of flooring surface to estrous behavior in lactating dairy cows as determined by radiotelemetric estrous detection. Pages 296-302 in Proc. 5th. Int. Dairy Housing Conf. ASAE, Fort Worth, TX.

Manninen, E., A. M. de Passillé, J. Rushen, M. Norring, and H. Saloniemi. 2002. Preferences of dairy cows kept in unheated buildings for different kinds of cubicle flooring. Appl. Anim. Behav. Sci. 75:281-292.

Phillips, C. J. C., and I. D. Morris. 2000. The locomotion of dairy cows on concrete floors that are dry, wet, or covered with a slurry of excreta. J. Dairy Sci. 83:1767-1772.

Phillips, C. J. C., and I. D. Morris. 2001. The locomotion of dairy cows on floor surfaces with different frictional properties. J. Dairy Sci. 84:623-628.

SAS Institute. 1999. SAS User's Guide. Version 8. SAS Institute, Inc., Cary, NC.

Somers, J. G. C. J., K. Frankena, E. N. Noordhuizen-Stassen, and J. H. M. Metz. 2003. Prevalence of claw disorders in Dutch dairy cows exposed to several floor systems. J. Dairy Sci. 86:2082-2093.

Stefanowska, J., D. Swierstra, J. V. van den Berg, and J. H. M. Metz. 2002. Do cows prefer a barn compartment with a grooved or slotted floor? J. Dairy Sci. 85:79-88.
Telezhenko, E., and C. Bergsten. 2005. Influence of floor type on the locomotion of dairy cows. Appl. Anim. Behav. Sci. 93:183-197.

Tucker, C. B., D. M. Weary, A. M. de Passillé, B. Campbell, and J. Rushen. 2006. Flooring in front of the feed bunk affects feeding behavior and use of freestalls by dairy cows. J. Diary Sci. 89:2065-2071.

Tucker, C. B., D. M. Weary, and D. Fraser. 2003. Effects of three types of free-stall surfaces on preferences and stall usage by dairy cows. J. Dairy Sci. 86:521-529.

USDA. 2002. Part I: Reference of Dairy Health and Management in the United States, 2002. Veterinary Services, National Animal Health Monitoring System, United States Department of Agriculture, Fort Collins, CO.

van der Tol, P. P. J., J. H. M. Metz, E. N. Noordhuizen-Stassen, W. Back, C. R. Braam, and W. A. Weijs. 2002. The pressure distribution under the bovine claw during square standing on a flat substrate. J. Dairy Sci. 85:1476-1481.

van der Tol, P. P. J., J. H. M. Metz, E. N. Noordhuizen-Stassen, W. Back, C. R. Braam, and W. A. Weijs. 2005. Frictional forces required for unrestrained locomotion in dairy cattle. J. Dairy Sci. 88:615-624.

Vokey, F. J., C. L. Guard, H. N. Erb, and D. M. Galton. 2001. Effects of alley and stall surfaces on indices of claw and leg health in dairy cattle housed in a free-stall barn. J. Dairy Sci. 84:2686-2699.

Weeks, C. A., P. W. McNally, and P. D. Warriss. 2002. Influence of the design of facilities at auction markets and animal handling procedures on bruising in cattle. Vet. Rec. 150:743-748. 